\title{
CHRONIC DISTURBANCES OF SMALL AND LARGE BOWEL FUNCTION
}

\author{
By Elizabeth De C. Falle,* M.B.(Lond), M.R.C.P., D.C.H., A. Morton Gill, M.D. (Lond.),
}

F.R.C.P., and Horace W. A. Post, M.D.(Lond.), D.M.R.E.

From the Gastric Clinic, West London Hospital.

Chronic disturbances of small and large bowel function are not only widespread but cause much unnecessary and protracted ill-health. They present with pain and give rise to a considerable problem both in general practice and in the gastric clinic at this hospital, where one-third of the new patients fall into this category.

Chronic dysfunction of the colon (tonic hardening of the colon, colon spasm or neurosis, irritable or unstable colon, functional or motor disorder of the colon) has been well recognised by a few physicians and surgeons as a cause of abdominal pain since colon spasm was first described by John Howship in 1830 .

Attention has only recently been drawn to similar disorders in the small intestine as a result of abnormal radiological findings in the small gut of patients with obscure abdominal pain. The abnormalities recorded were flocculation and resultant clumping of the barium, hypermotility, disorder of tone of the gut musculature and coarsening of the mucosal folds. In two papers (Glazebrook, 1952; MacPhee, 1953) the changes were found in patients who had been subjected to partial gastrectomy or vagotomy for peptic ulceration. Although some of these cases had developed other post-gastrectomy symptoms such as 'dumping, sore tongue, loss of weight and absorption defects, all were characterized by pain and bowel disturbances. In a third paper (Gill and Falle, 1952) similar radiological changes were described in eight patients with long-standing abdominal pain and disordered bowel action but in whom there was no evidence of malabsorption or of a lesion of the gastro-intestinal tract at operation. On the basis of these eight cases, the disorder was thought by the latter authors to be allied to colon spasm but of less frequent occurrence, to have distinguishing features of its own such as more

\footnotetext{
*Working with a grant from the Dan Mason Research Foundation, West London Hospital Medical School.
}

widespread pain, a more complex symptomatolog and much more resistance to treatment.

One hundred new patients from the gastrê clinic suspected of having a disturbance of irf testinal function have been examined and followes up over the 14-month period May $195^{2}$ to Juf 1953, primarily to determine the frequency of small bowel involvement. As it is difficult to divorce any discussion on the disturbances small bowel function from a wider discussion of intestinal dysfunction as a whole, and as mentiog of colonic dysfunction is only creeping into the latest editions of medical textbooks, the sympto matology, diagnosis, treatment, progress and aetiology of the whole group has been inclug in this paper.

The radiology and significance of the sma bowel changes will be considered first, while ans points arising in the course of the paper which beas particularly on the small gut will be emphasize and considered further in the final discussion.

\section{Radiology}

Out of the 100 patients, 75 had one or mors radiological examinations of the small intestine during 14 months. A colloidal preparation of barium sulphate was given in each case to a fasting patient. Films were taken after $\frac{1}{2}$ hour, I hous $I_{2} \frac{1}{2}$ hours and hourly thereafter until most of the barium had passed into the colon. The patient was allowed a light meal after the stomach was empty and this was usually at $2 \frac{1}{2}$ hours after the ingestion of the barium. Where any abnormalito was seen in the colon or when a duodenal ulcexo was later demonstrated by a further barium meal this has been noted under the relevant small gutf heading. The results are shown in Table $I$.

In 18 cases out of 75 one or more films of the small intestine were definitely abnormal (group I I3 showed clumping of the barium (in II this occurred in the ileum and in 2 in the jejunum Localized jejunal disorder in the nature of sma1 
TABLE I

RADIOLOGICAL Findings

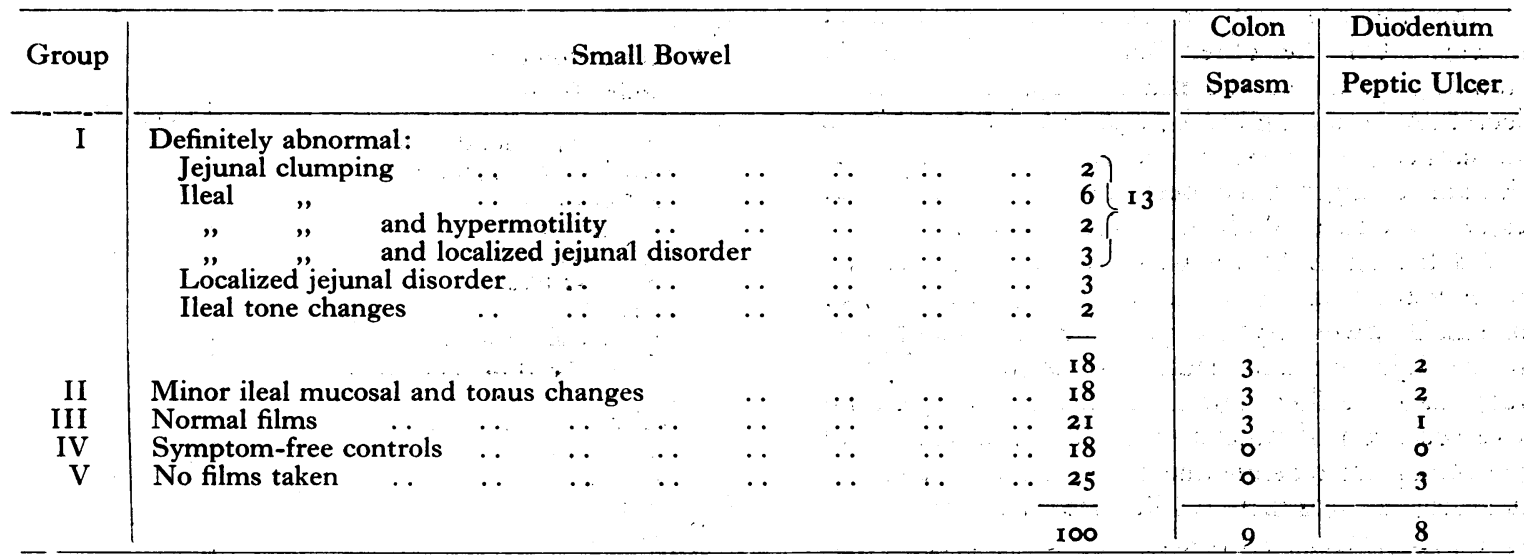

areas of dilatation or narrowing with coarsening of the mucosal folds was found in 6 patients, in 3 of whom clumping of the barium was also noted. Clumping was seen most commonly in the $1 \frac{1}{2}$-hour or $2 \frac{1}{2}$-hour film and before the patient had had any food. Ileal tone changes, that is areas of hyper or hypo-tonus, were present in 2 . In 2 cases the passage of barium through the small intestine was accelerated, the head of the barium column reaching the hepatic or splenic flexure within I hour. In the remaining cases, the head of the barium column reached the caecum between the normal time limits of 1 to 4 hours (Golden, 1950).

Eighteen cases (group II) had haziness of the mucosa and minor abnormalities of ileal tone, some loops of bowel appearing narrow and spastic, others dilated and hypotonic. In group.III were placed 2 I cases who had normal small bowel films despite symptoms. Eighteen patients fell into group IV. They also had normal small bowel films, but unlike the patients in group III, they were either cured or in the course of a complete remission at the time of their radiological examination and were therefore looked upon as suitable controls. In 25 patients the small intestine was not X-rayed (group V).

There was one patient in group III with normal small bowel films who on clinical grounds was suspected of small bowel dysfunction, but not a single abnormal film was found in any patient who was cured, that is, symptom-free and free of any treatment.

Marked colon spasm during the examination was noted in 3 patients in each of groups I, II and III (Table I), but was not present amongst the controls. Eight patients were later shown to have a duodenal ulcer, 2 in groups $I$ and II, $I$ in group III and 3 in group. V.

Until recently the deficiency pattern (Golden, I945), consisting of segmentation and flocculation of barium in the small intestine with loss of the normal feathery mucosal relief pattern, was thought to be a graphic representation of tone changes in the bowel wall and muscularis mucosae. This pattern has been demonstrated in patients with steatorrhoea, in nutritional deficiency, in gastro-intestinal allergy and in infants, but does not occur in normal adults.

. Frazer et al. (1949) and Astley and French (I95I) have shown that these appearances are due to flocculation and resultant clumping of barium regardless of the diameter of the gut,lumen or the tone of its wall. These workers have shown that barium can be thrown out of simple aqueous suspension by mucus, fatty acids and hypertonic solutions, but that flocculating resistent barium preparations remain in suspension to a much greater degree.

The degree of spasm or hypotonia in patients with intestinal dysfunction cannot therefore be gauged from the films which show clumping. However, clumping does not occur in a normal bowel, and the significance would seem to lie with the agent causing the flocculation. As our patients had no steatorrhoea, nutritional deficiency or gastro-intestinal allergy, and as they were fasting, neither fatty acids nor hypertonic solutions were present in their small bowel. The presence of an excess of mucus therefore remains as the most probable precipitating agent.

Wolf and Wolff (1947) have shown that certain emotional reactions, particularly those of anger, resentment, apprehension, anxiety, hostility and 
conflict, cause increased motor activity in the normal stomach, increased vascularity and rigidity of the mucosa and an increased secretion of mucus. On the other hand, inactivity of the stomach, pallor of the mucosa and inhibition of secretion were found to be associated with feelings of sadness, depression, discouragement or fear. Similar changes have been demonstrated in the colon by Grace, Wolf and Wolff (I95I).

All the small bowel patterns described in this investigation can be accounted for by a disturbance of small bowel physiology. The changes of tone in the jejunum and ileum, the coarsened jejunal folds and the flocculation of barium by an excessive secretion of mucus could all be the result of psychological tension due to resentment, anxiety, hostility or conflict, while the ileal hypotonia could result from depression or fear. Experimental work by Youmans (1949) shows that motor changes in the small bowel can also be brought about by reflex nervous impulses arising from disorder elsewhere in the gastro-intestinal tract.

\section{Symptoms}

The whole series of 100 patients was composed of 60 women of average age 43 years and 40 men of average age 37 years. The youngest patient seen was 21 years old, the eldest 69. Their build ranged from fat to thin and their colouring from ash blonde to black. Their symptoms had been present for:

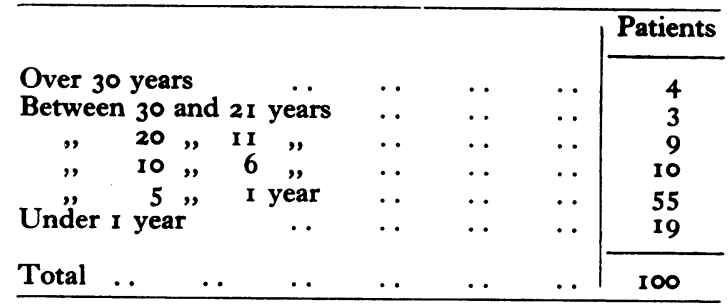

In two-thirds of the patients the symptoms occurred in attacks lasting hours, days or weeks at intervals of two weeks to several years. In the rest they were of daily occurrence.

In Table 2 the symptoms have been analyzed. The table shows that half the patients complained of epigastric pain (though 18 of these also had pain elsewhere in the abdomen), that 43 had lower abdominal pain sometimes localized to one or other iliac fossa, and that 19 had pain in the right or left hypochondrium. Fig. I shows these results graphically. When pain was radiated to the back it was felt in or adjacent to the midline at approximately the same horizontal level as the abdominal pain, pain under the costal margin being radiated between the shoulder blades,
TABLE 2

Analysis of Symptoms in 100 Patients

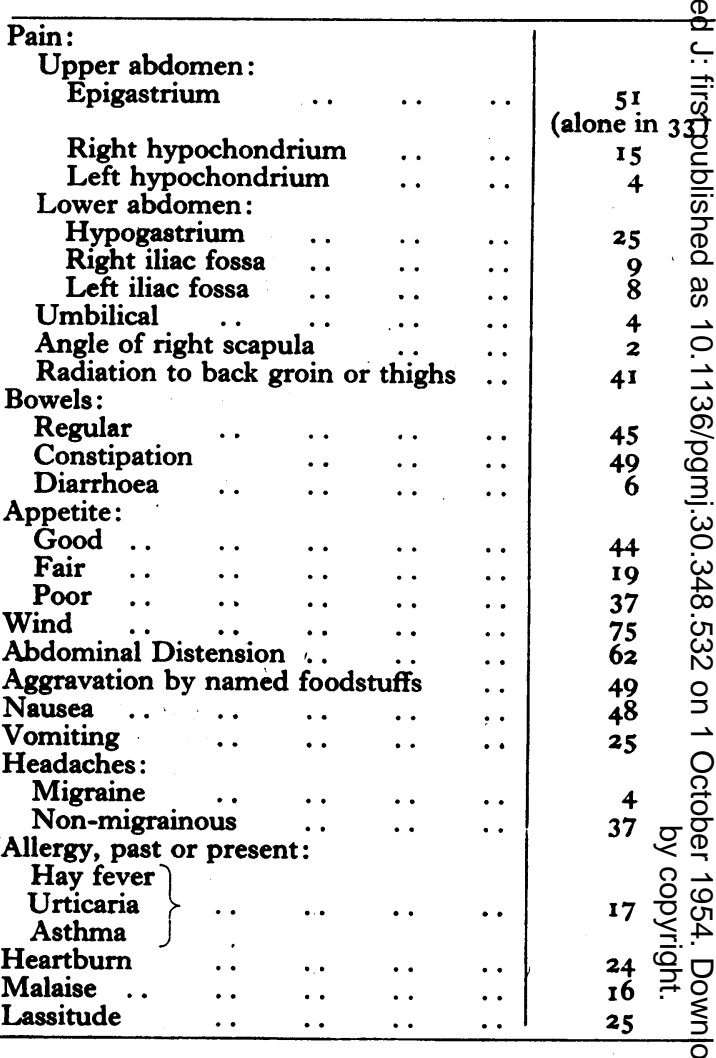

epigastric pain to the upper lumbar region and lower abdominal pain to the sacro-iliac joints Pain in the iliac fossae was sometimes radiated to the groin, and down the front or side of the thigh

It is interesting to note that, apart from pain which was the presenting symptom in every case. the most common complaint was wind, usually accompanied by gastric or colonic flatulence $(75)$. closely followed by abdominal distension (62) that half the patients were constipated, half were nauseated and half associated their indigestio with known foodstuffs. Twenty-four patients ha heartburn, only a small group suffered from an sort of allergic manifestation and migraine was uncommon. Twenty used adjectives or terms such as boiling, bubbling, knotted, fullness, lumps pressure, lead weights, heaviness and inflamed to describe their abdominal symptoms, many of which have been shown to represent the sensations arising from spastic, dilated, over-active or atonic loops of gas-filled gut (Bockus, 1943; Binghan et al., 1950). Malaise and lassitude were em@ phasized in a fair proportion, but judging by the number under treatment who felt ' ever so mucto better. in themselves' before their pain ha $\vec{\Phi}$ 


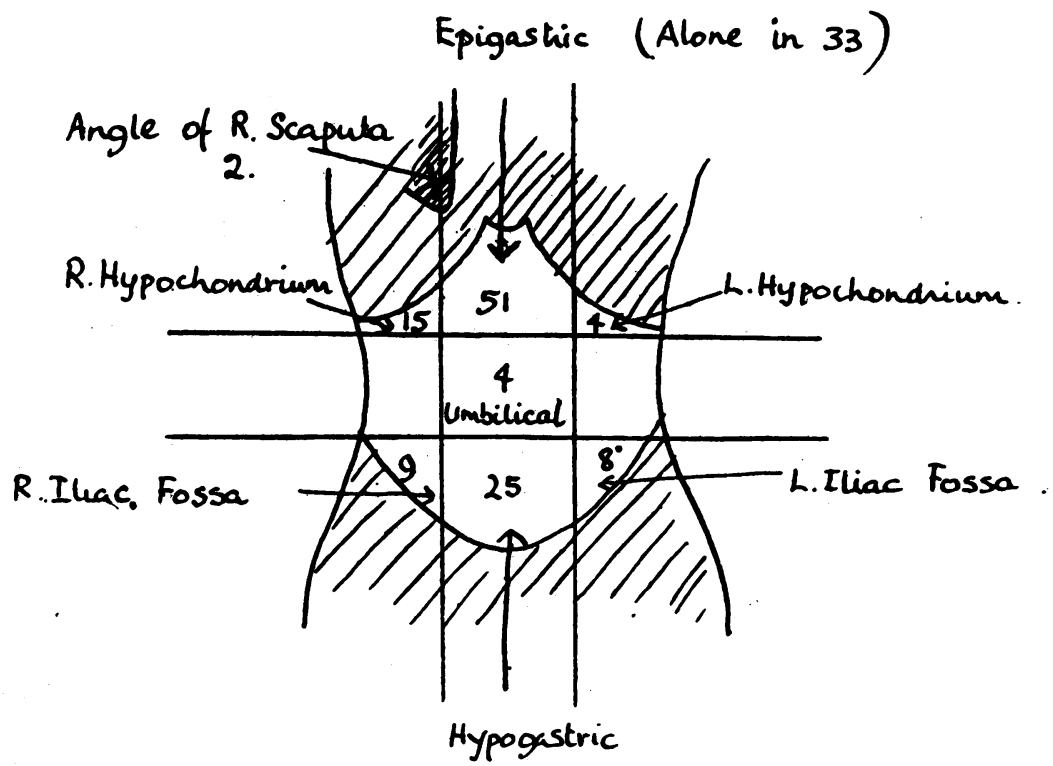

Fig. 1.-Distribution of pain.

disappeared, these symptoms were more common than the figures suggest. Eighteen gave a history suggestive of a duodenal ulcer and eight were eventually shown to have one. Seven patients had had duodenal ulcers in the past.

Forty-nine patients claimed that certain foodstuffs aggravated their symptoms, and these are

TABLE 3

Aggravation of Symptoms by Named Foodstuffs in 40 Patients

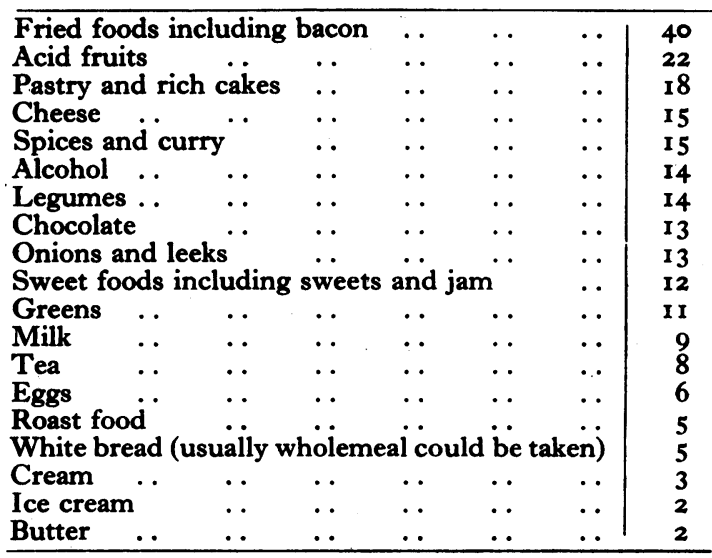

set out in Table 3. Fried foods, cheese, pastry, spices and onions may strain a healthy digestion, but in this group acid fruits, chocolate and sweet foods were also troublesome.

Table 4 shows facts relating to marriage, childbirth, the menstrual cycle and dysmenorrhoea in the 60 women concerned.
TABle 4

Out of 60 women:
40 were married.
30 had borne children.
I 7 had passed the menopause
I I were at the menopause.
9 suffered from dysmenorrhoea.

There was no gross difference in the incidence of symptoms between the radiological normals and the radiological abnormals, though it might be argued (and that was the clinical impression) that patients with changes in their small bowel had a greater range of symptoms, were more liable to radiation of their pain which tended to be more diffuse, to nausea, vomiting, to aggravation of their pain by named foodstuffs and to malaise.

\section{Signs}

With regard to the signs, 62 patients had evidence of colon spasm in that one or more segments of the colon were not only palpably in spasm or dilated with wind (e.g. the caecum) in the attacks but were tender. The distribution of the colon spasm is represented diagrammatically in Fig. 2. Twelve patients had epigastric tenderness and the remaining 26 had no abnormal physical signs in the abdomen. The distribution of signs among the patients with radiological abnormalities of the small bowel did not differ from that in the radiologically normal group.

Table 5 relates the signs to the symptoms and shows that epigastric tenderness is rarely found 


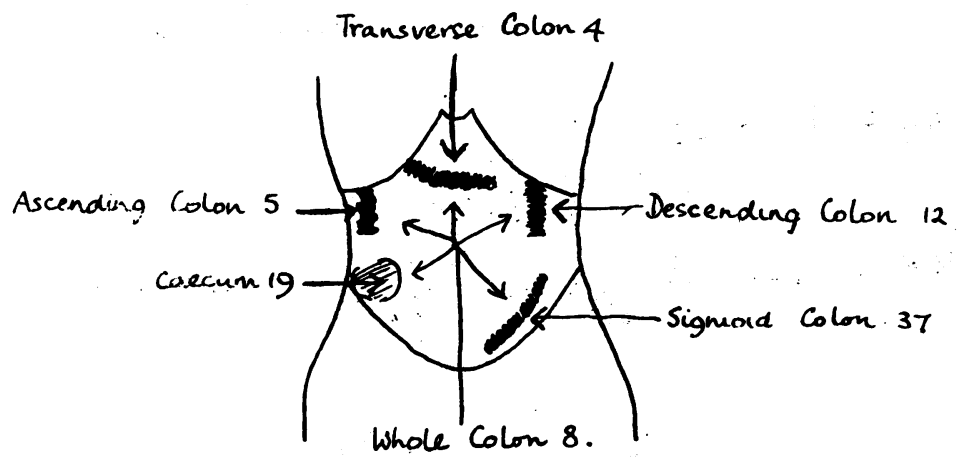

Fig. 2.-Distribution of colon spasm in 62 patients.

TABle 5

Relation of Signs to Symptoms

\begin{tabular}{|c|c|c|c|c|c|c|c|c|}
\hline & & & & & $\begin{array}{l}\text { Colon } \\
\text { Spasm }\end{array}$ & $\begin{array}{c}\text { Epigastric } \\
\text { Tenderness }\end{array}$ & Nil & Total \\
\hline Epigastric pain alone & . & - & . & . & I 5 & $8 / 4$ D.U. & ro & 33 \\
\hline Pain in hypogastrium & and/or & hy & hon & am & & & & \\
\hline and/or iliac fossa & . & .. & . & .. & 47 & 4 & I0 & 61 \\
\hline Umbilical pain alone & . & . & . & . & 0 & o. & 4 & 4 \\
\hline Scapular pain alone & $\cdots$ & $\cdots$ & $\cdots$ & $\cdots$ & 0 & 0 & 2 & 2 \\
\hline Total & $\cdots$ & . & . & .. & 62 & I2 & 26 & 100 \\
\hline
\end{tabular}

in these cases, but that, if it is accompanied by epigastric pain, then a duodenal ulcer should be strongly suspected.

Fourteen patients had skin lesions such as pruritus ani or eczema of hands, feet or face, which fluctuated with their abdominal symptoms:

\section{Psychological Aspect}

It is difficult to write scientifically about the psychological aspect, but as these cases fall into the hands of the general physician and are by common consent best treated by him (they rarely overlap into the realm of the psychiatrist), an attempt has been made to use terms and grouping significant to him. The personality of the patients concerned could be placed in one of four categories. There were 19 with the personality traits physicians have long associated with a duodenal ulcer, 20 with less robust personalities who all their lives had been nervous, excitable, easily fussed and worried, 20 who had psychoneurotic personalities (Barton Hall, I949) and 41 who were normally adjusted, having sufficient intelligence, temperamental stability, drive and emotional maturity to adapt themselves to the average demands of life.

The first category 'comprised 12 men and 7 women who were intelligent, able, conscientious and independent people, including 4 business men, 2 journalists, a professional musician, a cha a dressmaker, hairdresser, telephonist and dancin $\mathscr{Q}$ instructor, all managing their own businesses of large concerns. They were however tense given to worry, inclined always to be in a hurro and to be driving themselves to the limit of theip capacities. The second category included ro mer and 1o women whose intelligence lay at a lowe $\overline{\mathrm{r}}$ level of average normal. Though handicapped by their temperament, they knew what part if played in their reactions, had learnt to live wits it and to carry on their domestic lives and routine jobs satisfactorily. Nine men and I I women fee into the third category with psychoneurotic pero sonalities. These patients frequently found if impossible to adapt themselves to average environ mental circumstances and were inclined to break down with nervous symptoms of various sorts int which they had little insight. The fourth categor contained 22 men and 19 women whose intefor ligence and capabilities ranged between that of patients in the first and second categories.

The only psychological disturbances were if the emotional field, where they were present if 52 patients at their first visit to the clinic. Twentye nine were manifestly anxious, 13 of these having conversion symptoms outside their abdomen such as pressure headaches, palpitations, dizziness frequency, paraesthesiae or gripping sensations io 
TABle 6

Symptoms of Emotional Disturbance

\begin{tabular}{|c|c|c|c|c|c|}
\hline Personality Type & & Anxiety & Depression & $\begin{array}{c}\text { Conversion } \\
\text { Symptoms } \\
\text { Alone }\end{array}$ & Total \\
\hline $\begin{array}{l}\text { Duodenal ulcer type } \\
\text { Nervous excitable } \\
\text { Normally-adjusted } \\
\text { Psychoneurotic .. }\end{array}$ & $\begin{array}{l}\cdots \\
\cdots \\
\cdots\end{array}$ & $\begin{aligned} \text { I0 } & (4) \\
5 & (4) \\
5 & (3) \\
9 & \end{aligned}$ & $\begin{array}{l}2(1) \\
4 \\
9(5) \\
1\end{array}$ & $\begin{array}{l}0 \\
3 \\
3 \\
\mathbf{I}\end{array}$ & $\begin{array}{ll}12 & (5) \\
12 & (4) \\
17 & (8) \\
11 & \end{array}$ \\
\hline Total & .. & $29(\mathrm{II})$ & $16(6)$ & 7 & $52(17)$ \\
\hline
\end{tabular}

In brackets-Number under well-recognized stress.

their head, throat or limbs as well. Seven had conversion symptoms alone and 16 were depressed. Only 4 patients needed referring to a psychiatrist on this account.

Table 6 shows how these emotional disturbances were spread among the personality types already described, and shows in brackets the number in each group who had a well-recognised cause for their emotional upset ( 17 out of 52). These causes included marital disharmony, friction with in-laws, responsibility for, or care of, sick relatives or senile parents, enforced separation of married couples because of inadequate accommodation, and financial embarrassment of widowed or divorced wives. More rarely, the emotional upset arose through personal incompatibility with someone in authority at work. Hardly ever was the housing problem per se, long hours at work or tiresome daily travelling responsible. Most of the anxiety or depression, when not the result of cone of the above causes of stress, arose, particularly in the nervous patients, from a fear of the symptoms, fear that they were suffering from cancer or other serious organic illness.

Table 7

Relation of Small Gut Radiology to Personality TYPES AND EMOTIONAL SYMPTOMS

\begin{tabular}{|c|c|c|c|}
\hline \multirow{2}{*}{ Personality Type } & & Abnormal & Normal \\
\hline & & $\begin{array}{c}\text { Radiological } \\
\text { Groups } \\
\text { I and } \mathrm{II}^{*}\end{array}$ & $\begin{array}{l}\text { Radiological } \\
\text { Groups } \\
\text { III and IV }\end{array}$ \\
\hline $\begin{array}{l}\text { Duodenal ulcer type } \\
\text { Nervous excitable } \\
\text { Normally adjusted } \\
\text { Psychoneurotic .. }\end{array}$ & $\begin{array}{l}\cdots \\
\cdots \\
\cdots\end{array}$ & $\begin{array}{r}10(8) \\
8(8) \\
6(3) \\
12(10)\end{array}$ & $\begin{array}{rr}3 & (2) \\
8 & (3) \\
24 & (6) \\
4 & (4)\end{array}$ \\
\hline Total & $\ldots$ & 36 (29) & 39 (I5) \\
\hline
\end{tabular}

* The radiological Groups I and II are considered together as the figures are identical.

In brackets-Number of patients with anxiety, depression or conversion symptoms.

When the radiological changes in the small bowel were assessed against the personality types just described (Table 7), it was found that on one-sixth of the patients with abnormal X-r films (6 out of 36 ) had normally adjusted personali ties, whereas more than half of those with normab films (24 out of 39 ) were normally adjustedo Further, emotional disturbance (though presen in some of the latter patients) was much more ion evidence amongst all the personality types witwo abnormal films, both in the number involved $(28$ out of 36 ) and in degree. There were 8 patients with a frank anxiety state (4 among the duoden 8 ulcer personalities and 4 among the psychof neurotics), 7 of these having abnormal films the small bowel.

\section{Diagnosis}

The diagnosis of a chronic disturbance of intestinal function is a clinical one. In a large number of cases the diagnosis can be made con? fidently on the history alone, but in a few con? fusion arises over resemblance of the symptonis to those occurring with a peptic ulcer or wi chronic cholecystitis. Any gross loss of weigh acute change of bowel habit, fatty stools or los of blood would naturally favour the diagnosis of an organic bowel lesion. The classical history intestinal dysfunction is distinct. There is constant or intermittent pain over the colon or moge diffuse midline abdominal pain unrelated to the intake of food, accompanied in florid cases wind, distension, nausea, anorexia, chronic conistipation and anxiety. "The diagnosis is confirmed by palpation of a tender spastic segment of colsh (the sigmoid colon may be palpable in normal people, but it is not then tightly contracted tender). Radiological examination shows definite intestinal tone changes in a small proportion of the cases only; its chief value lies in the exclusign of an organic lesion.

A peptic ulcer should always be suspected when upper abdominal pain, occurring in attacks, has a constant time relationship to meals and is relieved by alkalis, regardless of the other sym 1 toms present. Though various articles of diget 
aggravate the symptoms of a patient with intestinal dysfunction, the time relationship is absent and the symptoms are not relieved by a gastric diet. An ulcer should be strongly suspected when there is localized epigastric tenderness. Symptoms of colon spasm may be superimposed on or alternate with those of a peptic ulcer and the need for treatment is equally great. They are often responsible for the residual abdominal symptoms after an ulcer has healed.

Diagnostic difficulty arose in those few patients without signs, who had non-specific epigastric pain only, or pain under the costal margin, particularly on the right side. In the former, the diagnosis may depend on the response to treatment after organic disease has been excluded by radiology. In the past some of the latter have been diagnosed as chronic cholecystitis on the grounds that their pain by its site and distribution appeared to arise in the gall bladder, because they were flatulent, full of wind, constipated and intolerant of fats and because a cholecystogram showed poor contraction of the gall bladder after a fatty meal. However, in many of them their history was exactly similar to patients with known colon spasm; they complained that wind appeared to be trapped under the right costal margin (in the hepatic flexure) and they responded to relief of their constipation and any spasm present more satisfactorily than to the administration of bile salts, antibiotics or biliary antiseptics. They were not jaundiced, did not have pale or fatty stools or a palpable gall bladder. The pain may appear only at the angle of the scapula, just as sigmoid pain may present chiefly over the sacro-iliac joint or cardiac pain predominantly at the wrist.

\section{Treatment}

Medicinal treatment alone helped these cases a great deal, but when it was combined with sympathetic hearing of the patient's social story, reassurance that organic disease had been excluded and explanation of symptoms, results were even better and justified the time expended. They did not respond to psychological treatment alone, even when psychological factors appeared to be playing a considerable part, neither did they respond to a gastric diet or to rest in hospital.

One of the primary requirements was to take a history which included details of home, family background and relationships, type and hours of work, leisure occupations, dietary habits and worries-sufficient in fact to form a mental picture of the patient in his own environment and to provide enough material to assess the stresses and strains to which the patient was or had been exposed in his daily life, together with his reactions to them. Indeed, this was not only a diagnostic step but a valuable therapeutic one, in that it gave the patient an opportunity to express some of his unspoken fears or anxieties which often he had not yet admitted to himself.

It was essential, where present, to break into the vicious circle produced by stress $\rightarrow$ symptoms $\rightarrow$ anxiety over symptoms $\rightarrow$ increase of pain $\rightarrow$ added stress. This could be done at several points. Firstly, after taking the history and making a thorough examination (radiography is necessary), the patient was convincingly relieved of the added anxiety that his symptoms were due to an incurable lesion. Secondly, he was led to understand that the normal rhythm of his intestinal movements was disturbed and that this disturbance was the cause of his pain. Thirdly, the patient needed to recognize the contributory part played in intestinal dysfunction by emotional disturbances when these were present. Many patients knew perfectly well in their heart of hearts that their symptoms were in part of nervous origin and needed only to have organic disease excluded to admit as much openly. Nevertheless, this was not sufficient to effect a cure. Fourthly, where a domestic or occupational worry was the cause of the patient's anxiety they were often able to work out a reasonable solution after discussion of their problems. Even those patients, especially the intelligent ones, who by their temperaments were driven to making life difficult for themselves, could with encouragement adapt their way of life.

Isogel (mucilaginous seeds), belladonna and phenobarbitone were found valuable medicaments. Most success attended the use of Isogel by mouth in doses I drachm nocte to 2 drachms t.d.s., whether the patient was initially complaining of constipation, diarrhoea or had regular bowel actions. This substance absorbs excess fluid in the lumen of the gut as well as preventing excessive reabsorption of water from the colonic-contents. The increased bulk of the intestinal contents aids the defaecation reflex and also appears to help in the restoration of harmony to an irritable bowel musculature. Isogel either by absorption of gas or by encouraging regular peristalsis largely did away with bloating, gastric and colonic flatulence. It was sufficient therapy for those whose symptoms were entirely due to constipation and was an excellent basis for further treatment in the others.

Eighty patients needed a local and general sedative as well. Compound tablets containing dry extract of belladonna, gr. $1 / 6$, and phenobarbitone, gr. $1 / 3$, were used for this purpose and were more useful than either of the drugs alone, though phenobarbitone, gr. $\frac{1}{4}$ to $\frac{1}{2}$ b.d. or t.d.s., replaced the compound tablet in those patients who were intolerant of belladonna.

In most cases the exclusion of fried fats and 
TABLE 8

Progress

\begin{tabular}{|c|c|c|c|c|c|c|}
\hline Personality Type & & Well & Improved & Unchanged & Unknown & Total \\
\hline $\begin{array}{l}\text { Duodenal ulcer type } \\
\text { Nervous excitable } \\
\text { Normally-adjusted } \\
\text { P sychoneurotic .. }\end{array}$ & $\begin{array}{l}\cdots \\
\cdots \\
\cdots\end{array}$ & $\begin{array}{l}13 \\
13 \\
30 \\
10\end{array}$ & $\begin{array}{l}5 \\
4 \\
7 \\
8\end{array}$ & $\begin{array}{l}0 \\
0 \\
2 \\
2\end{array}$ & $\begin{array}{l}\mathbf{I} \\
3 \\
2 \\
0\end{array}$ & $\begin{array}{l}19 \\
20 \\
41 \\
20\end{array}$ \\
\hline Total & .. & 66 & 24 & 4 & 6 & 100 \\
\hline
\end{tabular}

Complete recovery from symptoms was accoma

pastry from the diet was helpful at the onset of treatment together with any foodstuffs which ag gravated the patients' complaints.

\section{Progress}

In Table 8 the results of the treatment are shown divided amongst the personality types already described and apply equally to those patients with evidence of small bowel dysfunction; 66 of the patients are well, 45 out of these 66 need no further treatment or continue to take a small dose of isogel only, the other 21 have not yet been weaned completely of their belladonna and phenobarbitone tablets. The patients listed under improved have been partially relieved of their symptoms or they have had a less severe attack after a symptom-free interlude. Six patients did not return to the clinic and in four patients treatment was unsuccessful. These figures show that with sympathetic and careful management encouraging results can be obtained.

Those whose symptoms were solely due to longstanding constipation or to abuse of purgatives responded very rapidly to Isogel alone, but they needed to keep up the treatment indefinitely and some needed to be restrained from returning to intermittent doses of a strong aperient. Most of the rest needed to take the belladonna and phenobarbitone tablets regularly for three to twelve months (and a few even longer). No attempt was made to stop the tablets until any emotional disturbance was cleared up, then after three to six months' complete freedom from symptoms they were gradually reduced by one tablet per month before being finally omitted. Any return of symptoms during this time meant returning to the full dose for at least three more months. If the attacks were few and far between or after regular therapy had been stopped, resort to the tablets at the first sign of anything more than the most transient spasm of pain was found to abort the symptoms rapidly.

Prevention of symptoms was the goal to be sought after. The slighter and shorter the attacks and the longer the interval between them, the less liable were the patients to further attacks or relapses. Continuous dosage with $\mathrm{I}$ to 2 drachms of Isogel was most helpful in this connection. panied by a general feeling of well-being, by dis $\overline{0}$ appearance of all signs of food fads and of anxiety or depression. Segments of colon which werë spastic lost their tenderness and then became ims palpable in every case. A symptom-free patier黑 had no colon spasm, no epigastric tenderness or skin rash, he was smiling, calm and contented an was often found to have re-introduced into his diet on his own initiative previously offending foodstuffs.

\section{Aetiology}

Like other workers in this field we have found the aetiology of chronic disturbances of intestinap function not easy to determine, frequently mulo tiple and often unknown. Emotional factors were particularly difficult to assess, for anxiety and pression in a patient may cause the symptoms, nay be the result of them or may be entirely inciderfite Frequently the emotional state fluctuated in dependently of abdominal symptoms or of any welle recognized cause of stress, and relief of thi symptoms by medical means dispelled any anxiet or depression that was previously present. Con versely many patients whose attacks coincided with times of stress were never consciously disturbed b? this stress and certainly bore no evidence of emotional disturbance at any visit to the clinic.

Table 9a shows. under personality types the factors thought to play a major role in the aetiolog of attacks in 46 patients of this series. Althoug $\underline{\underline{B}}$ constipation where present nearly always cong tributed to the attacks it was thought to be solel responsible in 13. Only four of these patients were taking any sort of aperient. Aperients had been taken by 32 patients in this series but regular use of the more active ones such as cascara, syrup of figs, senna, vegetable laxatives, salts and bite beans was confined to 23. Although these drugg sometimes aggravated abdominal pain (often with out effectively relieving the constipation!) abuse of them was limited to very few patients and they consumption did not appear to be of aetiologic significance.

Twenty-six patients had attacks which coo incided with the periods when they were under pressure or recognizable stress at home or at wor 
TABLE 9

Aetiological Factors

\begin{tabular}{|c|c|c|c|c|c|c|c|c|}
\hline \multirow[b]{2}{*}{ Personality Types } & & \multicolumn{3}{|c|}{ A } & \multicolumn{3}{|c|}{ B } & \multirow[b]{2}{*}{ Total } \\
\hline & & Constipation & Stress & Menopause & Nil & $\begin{array}{c}\text { Stress at } \\
\text { Time of } \\
\text { First Attack }\end{array}$ & $\begin{array}{c}\text { Temperamentally } \\
\text { Given to } \\
\text { Worry }\end{array}$ & \\
\hline \multirow[t]{2}{*}{ 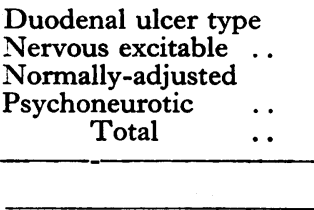 } & $\begin{array}{l}\ldots \\
\cdots \\
\cdots \\
\cdots\end{array}$ & $\begin{array}{r}0 \\
1 \\
10 \\
2 \\
13\end{array}$ & $\begin{array}{r}7 \\
5 \\
14 \\
0 \\
26\end{array}$ & $\begin{array}{l}1 \\
3 \\
3 \\
0 \\
7\end{array}$ & $\begin{array}{l}\circ \\
\circ \\
8 \\
\circ \\
8\end{array}$ & $\begin{array}{l}0 \\
0 \\
6 \\
4 \\
10\end{array}$ & $\begin{array}{r}\text { I I } \\
\text { 1 } \\
0 \\
14 \\
36\end{array}$ & $\begin{array}{l}19 \\
20 \\
41 \\
20 \\
100\end{array}$ \\
\hline & & \multicolumn{3}{|c|}{46} & \multicolumn{3}{|c|}{54} & \\
\hline
\end{tabular}

Humoral agents appeared to be responsible for symptoms in seven intelligent patients of good personality who for the first time at the menopause had become emotionally upset for no apparent reason. Marriage, childbirth, the phases of the menstrual cycle and the incidence of dysmenorrhoea had no constant bearing on the attacks of patients in this series, neither did they respond to the administration of ethinyl oestradiol or ethisterone.

This leaves 54 patients, Table $9 \mathrm{~b}$, in eight of whom no cause whatever was found for the attacks. Emotional factors may have played a contributory role in Io patients who were under stress at the time of their first attack and in a further 36 who were constitutionally given to worry.

Food allergy though seriously considered, played no part in the aetiology of these cases. It was evident from the patient's response to treatment that any discomfort arising after the ingestion of fats, sweet or spiced foods and vegetables was due rather to the exaggerated physiological response of an irritable small bowel. In the very rare case where food allergy is responsible for symptoms, this can only be determined by elimination diets; skin sensitivity tests are of no value in its diagnosis.

\section{Discussion and Conclusions}

The general outline of the symptomatology, diagnosis, treatment and aetiology of chronic intestinal dysfunction that emerges from this series of 100 cases is in keeping with the publications on colon spasm of such authorities as Ryle (I928), Spriggs (193I), Hardy (1934 and 1945) in this country, and of Jordan and Kiefer (I929), Jordan (1932) and Bockus and Willard (1933) in America.

In the past the source of the upper abdominal symptoms experienced by patients with colon spasm has not been identified with any specific portion of the upper gastro-intestinal tract, though the sphincters (Wilson, 1927) and the small intestine (Bockus, I944) have both been suspect.
Wilson (1927) and Hardy (1945) believed that these symptoms were reflex in origin (secondary: to colon spasm), whereas Bockus considered that they expressed a similar disorder higher up the gastro-intestinal tract. The role of the small intestine has not hitherto been fully investigated.

It has been pointed out in the radiological section of this paper that all the abnormal radiological appearances described can be accounted for by long-standing exaggeration or inhibition of normal small bowel activity. Our results indicate that an abnormal radiological pattern is always associated with symptoms. Although similar radiological appearances occur in a variety of pathological small bowel conditions, they are not found in healthy fasting adults or in symptom-free patients, and they are therefore significant.

Clinical experiments show that epigastric pain, a sensation of fullness and nausea may result from changes in activity of the stomach (Ryle, I93 I; Wolf and Wolff, I947), but that these symptoms may equally well arise from similar changes in the small intestine (Bockus, 1944). Sensations from the small bowel are felt as illdefined mid-line epigastric discomfort or pain, reaching down to include the umbilicus if the lower ileum is involved (Ray and Neill, 1947); the pain may be referred to the sides of the abdomen and to the back if the stimulus is intense or the pain threshold lowered (Bockus, 1943). It is therefore likely that some of the epigastric pain, nausea and fullness so frequently complained of by patients with a known disturbance of colonic function can be accounted for by concurrent dysfunction of the small intestine.

The fact that food so often aggravates the symptoms is another point in favour of small bowel involvement. Since the bulk and composition of the diet profoundly affect the basic secreto-motor activity of the normal small bowel, it is not surprising to find that certain foods exaggerate the physiological response in an irritable small bowel to a level productive of symptoms. 
It becomes clear from this investigation that small bowel dysfunction occurs more frequently and over a wider range of patients than was originally thought (Gill and Falle, 1952). Moreover, some degree of dysfunction is probably more widespread than the X-ray films suggest, for upper abdominal symptoms are not confined to the radiologically abnormal. (A parallel might be drawn with the colon where spasm can be demonstrated radiologically in comparatively few.)

Where the small bowel involvement was sufficient to give undoubted radiological signs the association between it and emotional disturbance was close. Clinical support for psychological tension as the prime aetiological factor was stronger here than anywhere else in the series. However, the possibility of a reflex mechanism cannot be ignored in those few patients with radiological signs who had no emotional disturbance, whose only detectable abnormality was a duodenal ulcer, gross constipation or a tender palpable colon. For in 'all experimental work linking emotional stress with changes in colonic activity, both in normal volunteers (Grace et al., I951; Almy et $a l .$, 1947) and in patients subject to colon spasm (Almy et al., 1949), it must be remembered that pain does not occur, though the visible and measurable changes in activity equal in quantity and quality those developed in a spontaneous attack.

Motor inco-ordination was put forward by Hurst (I9II) and again by Hardy (I945) as a cause of the pain experienced in colonic disorders. In 195 I Posey and Bargen found by balloon experiments that the intestines were made up of short functional segments normally slightly out of phase with one another. Their activity only coincided for short intervals during the forward transport of intestinal contents. If, however, a distal segment failed to fall into phase during the passage of a propulsive wave, physiological obstruction occurred and this was productive of pain. These findings support the conception that pain in disordered intestinal function arises from a dysyergia between adjacent functional units rather than from spasm or distension alone.

As regards intestinal dysfunction as a whole, a few points need emphasis. The psychological analysis of the whole group shows that intestinal dysfunction is no more confined to the psychoneurotic than is a duodenal ulcer, though more than half the patients concerned have in common a hypersensitivity, a liability to emotional conflict, to worry, anxiety and depression under greater or less strain according to the quality of their personality. Both duodenal ulceration and intestinal dysfunction occur over a similar range of personality type, both complaints may be pre气 cipitated by conscious or unconscious emotion stress or appear out of a clear sky, and one comp plaint may precede, supercede or co-exist withthe other.

The occurrence of intestinal dysfunction is ne cause for despair. Like a duodenal ulcer it relieved by suitable treatment and to a large exten can be prevented from recurring. Some cases of intestinal dysfunction, however severe their sympo toms appear at first, clear up with minimal treate ment while others respond only slowly and wiț perseverence. The patients reported here have not been followed up for long enough to estimaty the true relapse rate, but the tendency is towards complete recovery, for the incidence of intestina dysfunction falls off steeply over the age of $5 \overline{50}$ Those patients who are seen above this age are the few who have had no successful treatment i the past and who have not recovered spontaneouslyo

Chronic disturbances of intestinal function an common. In some instances they include both the small and large bowel (and probably the stomach, too); in others one particular section 6 the intestinal tract bears the brunt. Chron intestinal dysfunction is a complaint which canto diagnosed and treated, a complaint that is primarily a specialised psychiatric or allergic probe lem; it is allied to the problem of duodent ulceration and there is good reason to be optimists about its outcome.

\section{Summary}

I. A series of roo patients suffering from chronic disturbances of intestinal function have been examined and followed up during the $\mathrm{r}+\mathrm{F}$ month period May 1952 to July 1953 , primarit to determine the frequency of small bowel is. volvement.

2. The symptomatology, diagnosis, treatment, progress and aetiology of the whole group have been analyzed.

3. The significance of the radiological abnodmalities in the small bowel of 36 patients is dis cussed in conjunction with the clinical findings. Evidence is adduced that the small intestine plays an important part in the production of the uppe abdominal symptoms.

4. Emphasis has also been laid on the personality types affected, on the prognosis, and the similarity of the natural history to that peptic ulceration of the duodenum.

BIBLIOGRAPHY

ALMY, T. P., and TULIN, M. (I947), Gastroenterology, 8, $6 \bar{B}$ ALMY, T. P,, HINCKLE, L. E., BERLE, B., and KERN, BINGHAM, J. R., INGGELFINGER, F. J., and SMITHWIC包,

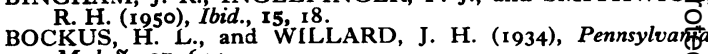
Med.'F., 37, 645 . 
BOCKUS, H. L. (1943), 'Textbook of Gastro-Enterology,' Vol. I, Philadelphia and London.

BOCKUS, H. L. (I944), Ibid., Vol. II.

FRAZER, A. C., FRENCH.'J. M., and THOMPSON, M.D.

(1949), Brit. F. Radiology, 22, 123. . (1952), Lancet, ii, 356.

GLAZEBROOK, A. J. (1952), Ibid., i, 895 .

GOLDEN, R. (1945), 'Radiological Examination of the Small Intestine,' Philadelphia and London.

GOLDEN, R. (1950), Brit. F. Radiology, 23, 390.

GRACE, W. J., WÖLF, S., and WOLLFF, H. G. (1951), "The Human Colon,' New York and London.

HALL, S. B. (1949), 'Psychological Aspects of Clinical Medicine,' London.

HARDY, T. L. (1934), Clin. $\mathfrak{F} ., 63,407,453$.

HARDY, T. L. (1945), Lancet, i, 5 19, 553 .
HURST, A. F. (1911), Ibid., i, 1051, $1119,1187$.

JORDAN, S. M., and KIEFER, E. D. (1929), Ұ.A.M.A., 93, 592.

JORDAN, S. M. (1932), Ibid., 99, 2234.

MACPHEE I. W. (1053), Lancet, i, 678 .

POSEY, E. L., and BARGEN, J. A. (195I), Amer. F. Med. Sciences,

RAY, B. R., and NEILL, C. L. (1947), Annals of Surgery, 126, 709.

RYLE, J. A. (1928), Lancet, ii, III5.

RYLE, J. A. (1931), L.ıncet, i, 737.

SPRIGGS, E. I. (I93I), Q.F.M., 24, 533.

WILSON, T. S. (1927), 'Tonic Hardening of the Colon,' London.

WOLF, S. G., and WOLFF, H. G. (1947), 'Human Gastric Function,' 2nd edition, New York.

YOUMANS, W. B. (I949), ' Narvous and Neurohumorel Regulation. of Intestinal Motility.' New York.

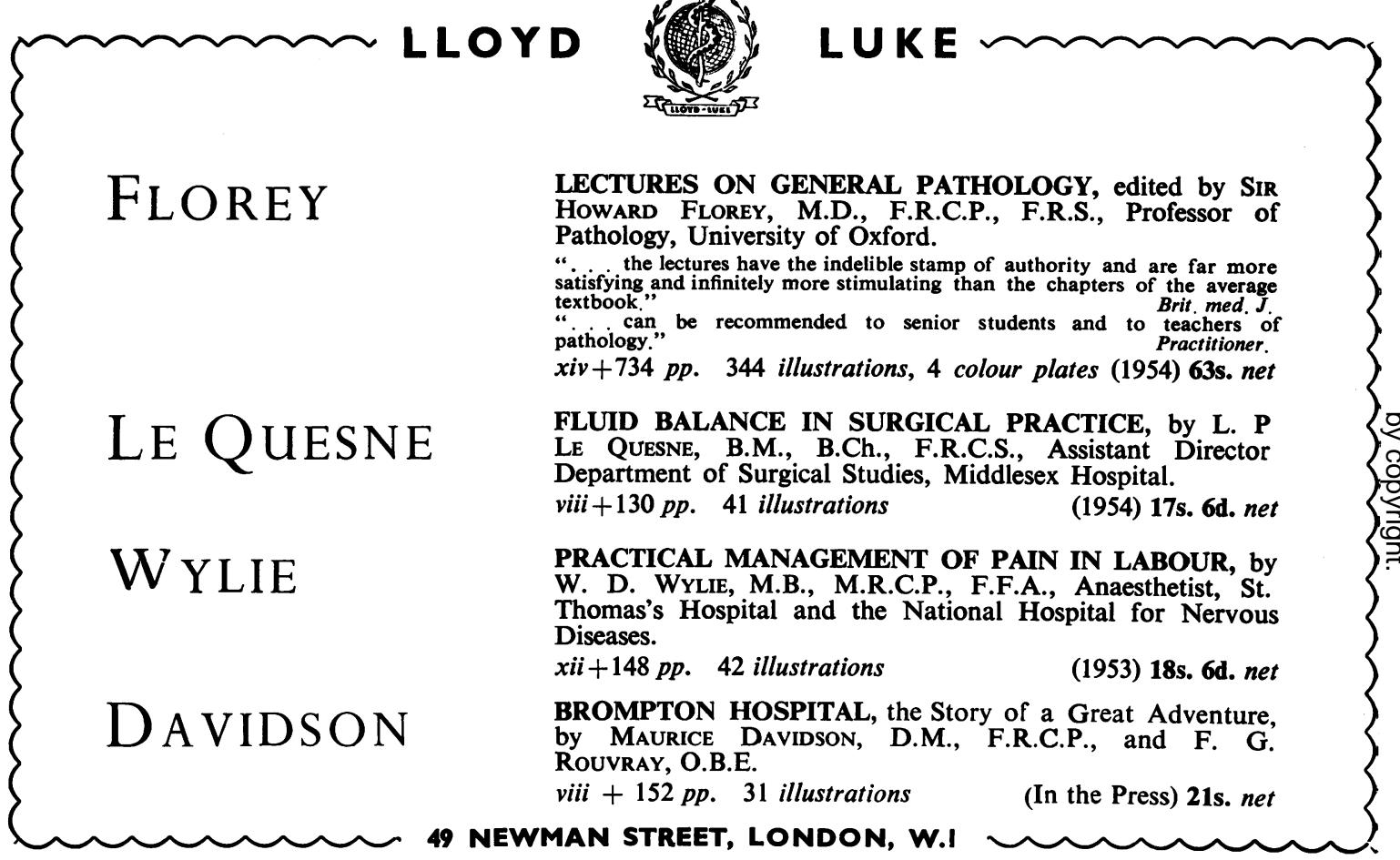

Bibliography continued from page $522-F$. B. Cockett, M.S., F.R.C.S.

\section{BIBLIOGRAPHY}

BARCROFT, H., and DORNHORST, A. C. (1948), f. Physiol., I08, 39.
BAZMAIIAN (1952), Surg. Gynae. Obst., $95,537$.

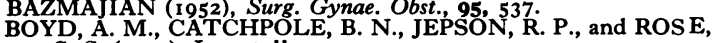
S.'S. (1953), Lancet, ii, I 13 .

BUXTON, R. W., and COLLER, F. A. (1945), Surgery, 18, 663.

COCKETT, F. B., and ELGAN-JONES, D. E. (1953), Lancet, i, 17.

CKETT, F. B. (I953), 'Pathology and Treatment of Venous Ulcers of the Leg,' MS. Thesis, London.

DOW, J. D. (195I), F. Fac. Radiol., 2, 180.

EGER, S. A., and CASPER, S. I. (1943), f. Amer. med. Ass., 123, 148.

GAY, J. (1868), ' On Varicose Disease of the Lower Extremities and its Allied Disorders,' Churchill, London.

GAY, J. (1867), Lettsomian Lectures.

GOLIGHER, J. C. (1953), Lancet, i, 96.

GRYSPEERDT, G., and COCKETT, F. B. (1953), Brit. $\mathcal{F}$. Radiol., 26, 329.

HOJENSGARD, I. C., and STURUP, H. (1949), Acta. Chir. Scand., 99, 133.
HOJENSGARD, I. C., and STURUP, H. (1952), Acta. Physiol. Scand., 27, 49.

HOMANS, J. (1916), Surg. Gynae. Obst., 22, 143.

HOMANS, J. (1917), Ibid., $24,300$.

LINTON, R. R., and HARDY,, I. B. (1948), Surgery, 24, 452.

LINTON, R. R.'(1953), Ann. Surg., Sept.

LUKE, J.'L. (1951), Surgery, 29, $38 \mathrm{I}$.

MCLACHLIN, J., and PATERSON, J. C. (195I), Surg. Gynae.

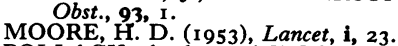
POLLACK, A. A., and WOOD, E. H. (1949), F. Appl. Physiol.,

POWELL, T., and LYNN, R. B. (195I), Surg. Gynae. Obst., WALK, 953 . WARREN, R., WHITE, E. A., and BELCHER, C. D., (1949),

Surgery, 26, 435 .
WARWICK, W. T. (1931), ' The Rational Treatment of Varicose Veins and Varicocele,' Faber, London. WELLS, H. S., YOUMẢNS, J. B., and MILLER, D. G. (1938),

WRIGHT, H. PAYLING (1952), Brit. med. Bull., 8, 187.

WRIGHT, H. PAYLING (1952), Brit. Heart. F., 14, 325.

WRIGHT, R. B. (I953), Lancet, ii, 1273. 